\title{
Macroscopic Findings Assessment Character Result in Standard Format
}

National Cancer Institute

\section{Source}

National Cancer Institute. Macroscopic Findings Assessment Character Result in

Standard Format. NCI Thesaurus. Code C119874.

The standard character or string for representation and reporting of macroscopic findings data. 